I Universidade Federal de Juiz de Fora (UFJF), Departamento

de Ciências Sociais, Juiz de Fora, MG, Brasil

joaodulci@gmail.com

https://orcid.org/0000-0003-215I-8805

João Assis Dulci'

\title{
CRISE, EMPREGO E RENDA NA INDÚSTRIA AUTOMOTIVA: OS CASOS DO SUL FLUMINENSE, CAMAÇARI E GRANDE ABC PAULISTA EM PERSPECTIVA COMPARADA
}

A indústria automotiva brasileira aportou no país no início do século $\mathrm{XX}$, com plantas de capital estrangeiro no modelo CKD. Até a década de I980, os fabricantes ditos nacionais, embora de capital estrangeiro, operaram em regimes protegidos por reserva de mercado, com parcas interrupções. Durante as décadas de 1980 e I990, o mercado brasileiro se abriu, consolidando novos processos de investimentos estrangeiros e de instalação de novas plantas, sob a égide das políticas setoriais. A Câmara Setorial da Indústria Automotiva representou uma etapa de planejamento sobre o setor em questão, definindo critérios e objetivos para proteger o emprego e a indústria nacionalmente instalada (Oliveira, I999). A consolidação do Mercosul como mercado consumidor ampliado, as infraestruturas industrial, viária e portuária brasileiras, superiores em comparação àquelas de nossos vizinhos sul-americanos, e as medidas de internalização dos investimentos especificamente automotivos representada pelo Novo Regime Automotivo foram importantes motivações para investimentos (Cardoso, 2006). A "guerra fiscal", definidora de uma postura do governo federal distante das disputas e reificadora de desigualdades, e os inúmeros incentivos diretos e indiretos, públicos e privados, definidos em escalas subnacionais foram os elementos que deram destino à instalação das plantas industriais (Comin, 200I; Dulci, 2002; Nabuco et al., 2002; Arbix, 2006 etc.).

A partir de 2012, surge uma terceira onda de investimentos, pautada por novas políticas públicas específicas para o setor, no período de vigência do 
Programa Inovar-Auto. Datam desse período a vinda de algumas montadoras, como a Hyundai Heavy Industries e a Nissan, para o vale do Paraíba fluminense, inversões em ampliações de fábricas e construções de plantas de autopeças, como a fábrica de motores da Ford em Camaçari, entre outras iniciativas.

As condições básicas para seu aporte foram a reestruturação produtiva e a reespacialização industrial de países do centro em direção aos semiperiféricos, que ocupam as funções de novos mercados consumidores potenciais, plataformas exportadoras e greenfields em suas várias configurações (Radosevic \& Rozeik, 2005). A expansão industrial em direção ao leste europeu, ao México e à América do Sul fez com que se exportassem milhares de empregos para "novas" regiões automotivas (Van Tulder \& Ruigrok, I998; Olivera, 200I; Vega, 2004; Radosevic \& Rozeik, 2005; Covarrubias, 2006).

Diante de tal cenário, o que se propõe neste trabalho é analisar a situação da cadeia industrial automotiva desde a explosão da crise econômica mundial (em 2008, nos Estados Unidos) até os dias atuais e identificar o reflexo da crise nos empregos da referida matriz produtiva. À crise econômica do final da primeira década do século XXI, soma-se a crise política adensada a partir das eleições de 2014 no país. Para tanto, replica-se o modelo adaptado, utilizado alhures, mapeando a cadeia produtiva automotiva (Torres \& Cário, 20 2; Dulci, 20I5, 20I8) a partir dos clusters brasileiros. O objetivo aqui é identificar quais trabalhadores foram desligados pelas montadoras, quais foram mantidos e quais atividades econômicas foram mais atingidas. A hipótese é de que os trabalhadores diretamente ligados à produção, com menor demanda de qualificação, são os primeiros demitidos. Simplifica-se aqui, portanto, a formulação de Adalberto Cardoso (I998), em trabalho que analisa as reestruturações sistêmicas e a experiência acumulada ante as capacitações adquiridas em qualificação formal, a fim de testá-la novamente em um contexto crítico, em que a crise é externa à configuração produtiva per si, mas ao mesmo tempo afeta e é afetada pelas possibilidades de reconfiguração produtiva. Por isso, escolhemos para ilustrar a situação brasileira a estratégia comparada, com dois "novos" territórios automotivos (o sul do estado do Rio de Janeiro e o polo industrial de Camaçari, na Bahia), ante o "tradicional” território do Grande ABC Paulista, de maneira a investigar se há diferenças no comportamento corporativo nas plantas que sofreram processos de reestruturação em relação àquelas já instaladas nos moldes mais modernos. Os dados utilizados compreendem os anos de 2007 a 2017 (o ano imediatamente anterior à crise internacional e o ano mais recente com informações disponíveis, respectivamente).

Apresenta-se um breve histórico da trajetória recente da indústria automotiva no mundo e no Brasil para localizar as formas de inserção dos presentes casos, que serão explorados em seguida. Após uma discussão sobre a crise mundial de 2008, joga-se luz sobre os casos em análise e os dados relativos ao emprego no setor automotivo, com uma análise específica sobre um 
caso aparentemente desviante. Por fim, são verificadas em quais regiões a hipótese proposta se sustenta, e em quais se faz necessária sua reformulação.

\section{A TRAJETÓRIA RECENTE DA INDÚSTRIA AUTOMOTIVA}

A indústria automotiva brasileira é fruto de três conjunturas distintas. A primeira, dos modelos CKD de início do século à consolidação do compromisso fordista. A segunda, no desmanche do compromisso fordista como regime consolidado de acumulação, conforme compreendido pela teoria da regulação (Lipietz, I989; Boyer, I990, entre outros), ${ }^{\mathrm{I}}$ até a formulação dos programas nacionais de incentivo fiscal, nacionalização da produção e upgrading tecnológico dos anos I990. A terceira, sob a égide de mais um pacote de incentivos a partir do Inovar-Auto (20I 2), num novo movimento de transnacionalização de empregos e plantas automotivas.

A reespacialização industrial das segunda e terceira conjunturas é fortemente ligada ao desmanche do compromisso fordista e, mais intensamente, ao avanço liberal nos países centrais (Dulci, 20I6). Países outrora semiperiféricos (casos de Japão, Coreia do Sul e os “Tigres Asiáticos"), países centrais reconstruídos no pós-guerra e casos bem-sucedidos de social-democracia, como Alemanha, França e Suécia, avançaram sobre mercados tradicionais do setor (mais notadamente os Estados Unidos, a partir da década de I970), principalmente com base em processos bem-sucedidos de reestruturação produtiva em suas plantas automobilísticas (Boyer \& Freyssenet, 2003). A gradual perda de competitividade dos automóveis norte-americanos foi agudizada com as duas crises do petróleo (Boyer, I990), tornando os veículos de alto consumo de combustível daquele país extremamente custosos para seus donos. Além disso, a evolução tecnológica em termos de competitividade industrial e as inovações com relação a métodos e organização fabril impuseram uma posição defensiva às tradicionais montadoras de Michigan (Boyer \& Freyssenet, 2003). Além da invasão aos Estados Unidos, acentuou-se a competição das montadoras por novos mercados. A esse processo somam-se a queda da hegemonia soviética no leste europeu (Van Tulder \& Ruigrok, I998; Radosevic \& Rozeik, 2005), questões de política imigratória e de reestruturação produtiva nas plantas centro e norte-mexicanas (Olivera, 200I; Vega, 2004; Covarrubias, 2006) e a exploração de mercados consumidores potencialmente expansíveis para o continente sul-americano, como o caso brasileiro, o que gerou uma concentração subcontinental de plantas em nosso país (Ciccolella, I992; Novick, 200 ; Cardoso, 2006). Todos esses movimentos levam em conta, naturalmente, o aumento dos lucros mediante redução de gastos e aumento da eficiência produtiva, configuração facilitada pelo desenvolvimento de tecnologias informacionais, em processos de compressão de tempo e espaço (Castells, 2007; Harvey, 2008), instrumentos fundamentais para as transformações do regime de acumulação global (Harvey, 20I I). ${ }^{2}$

A partir dos processos de transformações fabris, as multinacionais do setor automotivo gestaram configurações produtivas que foram exportadas 
para diversos países, no espírito de ocupação de novos espaços de produção - os chamados greenfields (Van Tulder \& Ruigrok, I998; Radosevic \& Rozeik, 2005) - e de redução de mão de obra. Se no Leste Europeu e no norte do México configuram-se mais claramente casos de greenfields stricto sensu, o Brasil constitui-se num modelo híbrido, em que internamente se reproduz a dualidade brownfield $\mathrm{x}$ greenfield, embora não fique evidente que algumas das regiões escolhidas pelas multinacionais do setor sejam exatamente greenfields. ${ }^{3}$ No nível escalar, é possível transpor o conceito em termos subnacionais, indicando, como faz ampla literatura sobre trabalho no Brasil, que o Grande ABC Paulista se tornou um brownfield, o que não identifica, entretanto, as "novas" regiões automotivas automaticamente como greenfields. Descendo mais um degrau na escala, mirando as dimensões meso e microrregional, temos outras relações, como no caso do vale do Paraíba fluminense, onde o município de Volta Redonda representa um brownfield diante de Resende e Porto Real, greenfields. Ou, de forma mais adaptada, podemos reconceituar a noção de greenfield em termos setoriais de produção, denominando tanto o sul do estado do Rio de Janeiro quanto Camaçari, na Bahia, greenfields setoriais (Dulci, 20I5), uma vez que a tradição industrial de ambas as regiões data das décadas de I940 e I970, respectivamente.

Podemos afirmar, portanto, que as décadas de i 990 a meados de 2000 e de 20 Io representaram novas ondas de investimentos estrangeiros no Brasil, graças à conjunção dos fatores aqui apontados.

\section{OS TRÊS CASOS}

Os casos aqui estudados inserem-se na expansão da esteira produtiva global, em diferentes momentos. As primeiras plantas novas foram instaladas a partir da segunda metade da década de I990. No entanto, buscaremos comparar o comportamento das plantas instaladas nos moldes "modernos", reestruturadas desde seu início, com a região que mais claramente se conforma à noção de brownfield brasileiro, o Grande ABC Paulista, buscando identificar diferenças de comportamento para responder à nossa pergunta sobre o emprego automotivo a partir da recente crise mundial, controlando as variáveis novas plantas e plantas tradicionais reestruturadas.

O Grande ABC Paulista é o mais pujante cluster industrial brasileiro, muito favorecido por incentivos do governo federal e pelo plano de metas de Juscelino Kubitschek, cuja opção pelo rodoviarismo contribuiu para impulsionar a matriz automotiva. As grandes montadoras transbordaram em fábricas autopartistas, embora a região tenha abrigado também fábricas de outras matrizes. Entre as décadas de i970 e I980, o ABC sofreu com os choques do petróleo, com a crise fiscal da ditadura, com o início da abertura do mercado brasileiro, a decrescente competitividade de suas fábricas e más decisões corporativas quanto ao mix de produção industrial (Appy, I993; Ferraz et al., I996), em estratégias de inovação produtiva e não de produto (ver Boyer, I990), resultando em de- 
semprego. O Grande ABC Paulista, outrora o “coração do 'milagre brasileiro'”, "começou a experimentar, a partir do início da década de 80, um acelerado processo de crise que se expressa no fechamento de unidades produtivas e transferência para outras regiões, retração do investimento, diminuição do volume de emprego, queda do rendimento médio da população, redução da participação no PIB industrial brasileiro" (Leite, 2000: 89).

Se a produção e o número de empregos na região observaram uma trajetória crescente entre I970 e I980, as oscilações na década de I980 desembocaram num cenário crítico já nos primeiros anos da década de I990. As Câmaras Setoriais (ver, por exemplo, Oliveira, I993, I999), a manifestação de trabalhadores brasileiros junto à Ford em Detroit e as lutas contrárias às reestruturações defensivas na região (Bedê, I997) conduziram o poder público local a novas estratégias de recuperação regional. A ascensão de um representante sindical do $A B C$ à Presidência da República, a criação do Conselho Nacional de Desenvolvimento e do Plano Nacional de Desenvolvimento Regional, além da acumulação de experiências da parte do trabalho organizado complementaram o importante esforço da região para a reversão de trajetória fortemente negativa, recuperando, em parte, o desenvolvimento econômico local (Ramalho \& Rodrigues, 2010). As melhoras na conjuntura econômica consolidaram esse processo, invertendo o sentido negativo e elevando os níveis de produção, as exportações e os licenciamentos de automóveis no país. A ampliação do crédito ao consumidor, incluindo linhas de financiamento para automóveis usados, as alterações no mix produtivo e a instalação de novas plantas no país configuraram um cenário que parecia sólido até finais da década de 2000 . O esforço para adiar os sinais de crise, em razão das medidas anticíclicas adotadas de pronto pelo governo federal, foi bem-sucedido na salvaguarda dos empregos da região, até meados da década de 20 ı.

O Polo Industrial de Camaçari, por sua vez, é resultado dos esforços para a redução da desigualdade de desenvolvimento regional no Brasil, a partir da Superintendência do Desenvolvimento do Nordeste (Sudene), do Plano de Desenvolvimento da Bahia (Plandeb) e de financiamento do Banco Nacional de Desenvolvimento Econômico e Social (BNDES), a partir do II Plano Nacional de Desenvolvimento (II PND) (Mendes, 2006; Andrade, 2009; Dulci, 20I5). Inicialmente pensado como um polo petroquímico de refino de petróleo da Petrobras - na época denominava-se Complexo Petroquímico de Camaçari (Copec) -, o polo iniciou suas operações, paulatinamente atraindo indústrias do setor químico (como borrachas e plásticos). Ultimamente, iniciativas do setor farmacêutico e de química avançada aportaram no polo, que acabou por receber, na virada do século, a planta da Ford Motors do Brasil (Dulci, 20I5).

Ao longo de sua existência, acentuaram-se os problemas de desigualdades regionais baianas, com surtos de desarranjo urbano e crescente hiato na 
estratificação social, não apenas no município de Camaçari, mas em toda a Região Metropolitana de Salvador, gerando uma hierarquização habitacional, em que os trabalhadores do chão de fábrica residem em Camaçari, Lauro de Freitas, Dias d'Ávila e Candeias, e os dirigentes na capital. O município de Camaçari divide-se em três regiões: o Centro, onde se concentram os camaçarienses, o Polo e o litoral, onde se situam os condomínios de luxo (Castro, I988; Pessoti \& Pessoti, 20Io; Dulci, 20I5).

A instalação da planta referente ao Projeto Amazon, deu-se após o imbróglio referente aos incentivos oferecidos à montadora pelo então governador do Rio Grande do Sul, Antônio Britto, que havia sido derrotado por Olívio Dutra. A Ford desistiu da construção da fábrica naquele estado e recebeu a oferta de incentivos, financiamentos, isenções e doação de terreno por parte do governo da Bahia, em debates capitaneados por proeminentes políticos locais, que asseguraram a aprovação da emenda ao Novo Regime Automotivo especial para o Norte, Nordeste e Centro-oeste, no Congresso (Dulci, 20I5). A Ford de Camaçari tem capacidade de produção de $250 \mathrm{mil}$ veículos/ano (Ford.com, acessado em 2013).

Por fim, o vale do Paraíba fluminense, microrregião composta pelos municípios de Barra Mansa, Itatiaia, Pinheiral, Piraí, Porto Real, Resende, Quatis, Rio Claro e Volta Redonda, conforma o terceiro caso aqui analisado. Apesar das disparidades de desenvolvimento entre os municípios, percebe-se um enorme fluxo de pessoas e relações que permite identificar a região como um corpo integrado (IBGE, 2008). Com base na tipologia proposta por Anssi Paasi (2000), afirma-se que o vale do Paraíba fluminense é uma região resultante de um processo de acumulação de capital, em decorrência da produção desigual dos lugares, mas sem uma prévia demarcação de fronteiras, o que se mostra muito claro pelos processos históricos que têm a implantação da Companhia Siderúrgica Nacional como propulsora. É também uma região historicamente construída por inúmeros tipos de relações e um espaço de conformação de práticas sociais, institucionalizadas por meio de um processo pelo qual uma unidade territorial se torna uma entidade estabelecida na estrutura espacial e pode, portanto, ser identificada em termos de práticas institucionalizadas e consciência social nas esferas política, econômica, cultural e administrativa, sendo continuamente reproduzidas nessas práticas (Paasi, 2000).

A história produtiva do vale do Paraíba fluminense foi muito marcada pela Companhia Siderúrgica Nacional. Desde sua instalação, na década de I940, que resultou na emancipação do distrito de Volta Redonda, até sua privatização, em I993, momento de profundas transformações na região. A inserção na esteira automobilística mundial se deu logo do início da "guerra fiscal", em meados dos anos I990, quando do anúncio das intenções da Volkswagen de implantar uma fábrica de caminhões e ônibus no Brasil. O estado do Rio de Janeiro, mediante uma força-tarefa, e a prefeitura de Resende empenharam-se em proto- 
colos de atração industrial, incentivos, isenções, construção de subestações de energia e infraestrutura viária para consolidar seus esforços (Lima, 2005; Ramalho, 2005, Santana, 2010, Dulci, 2015, entre outros). Pouco depois de iniciadas as operações do consórcio modular da Volks Caminhões e Ônibus, em Resende, o governo estadual entrou na disputa por mais uma planta para a região: a PSA Peugeot-Citroën, que residiria no município recém-emancipado de Porto Real (Santana, 2010),4 processo que envolveu disputas políticas, protagonizadas por empresários e lideranças locais, conformando o município de maior PIB per capita do estado fluminense na época (Lima, 2005).

As duas fábricas possuem trajetórias desiguais em relação ao seu potencial sucesso na região. Em função de políticas públicas voltadas para desenvolvimento tecnológico do óleo diesel brasileiro, a Volks Caminhões e Ônibus observou queda acentuada em sua produção e seu número de vendas por alguns anos ao longo da primeira década deste século. A PSA, em função de oscilações estratégicas, anunciou e adiou algumas vezes a ampliação de sua produção. Pode-se dizer, porém, que são fábricas consolidadas, bem como tiveram efeito na geração de externalidades positivas para o vale do Paraíba fluminense, o que se materializou na atração de outras três novas montadoras. Apesar disso, pela própria configuração das plantas no sentido de fornecedores cativos (Gereffi, I994), a integração produtiva não é propriamente um resultado observado.

\section{A CRISE}

A crise mundial de 2008 teve como origem o mercado imobiliário dos Estados Unidos e seu sistema de (re)financiamento de hipotecas (Dulci, 2009). Embora o mercado imobiliário daquele país já desse sinais de problemas desde finais da década de I990, a tomada de ações só ocorreu quando os grandes centros financeiros foram atingidos (Harvey, 20I I). O problema não se resumiu à incapacidade de pessoas físicas em quitar seus débitos bancários, mas conformava uma complexa engrenagem de financiamentos, refinanciamentos e seguros de débitos, incluindo negociação de dívidas de terceiros como ativos no mercado financeiro. "No epicentro do problema estava a montanha de títulos de hipoteca 'tóxicos' detidos pelos bancos ou comercializados por investidores incautos em todo o mundo. Todo mundo tinha agido como se os preços dos imóveis pudessem subir para sempre" (Harvey, 20I I: Io). A falência de importantes bancos de investimento, a falta de regulação e a interconexão global transformaram a crise num rastilho de pólvora espalhado por todo o mundo. Como o próprio Harvey aponta, a crise tomou dimensões insustentáveis, envolvendo diversos agentes econômicos, de diferentes matrizes e nacionalidades:

No fim de 2008, todos os segmentos da economia dos EUA estavam com problemas profundos. A confiança do consumidor despencou, a construção de habitação cessou, a demanda efetiva implodiu, as vendas no varejo caíram, o desemprego aumentou e as lojas e as fábricas fecharam. Muitos dos tradicionais ícones da indústria dos 
EUA, como a General Motors, chegaram perto da falência, e um socorro temporário das montadoras de Detroit teve de ser organizado. A economia britânica estava igualmente com sérias dificuldades, e a União Europeia foi abalada, mesmo com níveis desiguais, com a Espanha e a Irlanda, juntamente com vários dos Estados orientais europeus que recentemente aderiram à União, mais seriamente afetados. A Islândia, cujos bancos tinham especulado nesses mercados, ficou totalmente falida (Harvey, 20I I: I3)

Foi apenas questão de tempo para que países cujas trajetórias de crescimento aparentemente ilimitadas entrassem na dança. A China, detentora de bilhões em títulos da dívida norte-americana, interrompeu investimentos, atingindo frontalmente a indústria siderúrgica brasileira. Uma retração geral do crédito parecia iminente ao redor do mundo. No Brasil, uma agenda anticíclica foi desenhada pelo governo federal no sentido de estimular o consumo, com a conservação do crédito a pessoas física e jurídica, manter os incentivos diretos e indiretos a setores-chave na indústria, em troca do compromisso de os setores não demitirem, além de alardear um clima de solidez dos instrumentos de mercado brasileiros, mesmo ante a grave crise mundial. Em meio a um cenário desolador em termos de produto interno bruto das economias mundiais, o Brasil observou crescimento de 5,2\% em 2008, o,9\% em 2009 e 7,5\% em 20 Io.

Não há ainda hoje consenso sobre o custo que as políticas anticíclicas tiveram na economia brasileira. Fato é que, a partir de 2013, o PIB nacional iniciou uma trajetória depressiva que permanece. A extensão dos incentivos fiscais parece ter tido um contraefeito em termos de arrecadação pública. À crise econômica mundial, somou-se a crise política instaurada após a reeleição de Dilma Rousseff, em 20I4, culminando em seu impeachment em 2016. Seu sucessor, Michel Temer, conduziu processos de flexibilização, esvaziamento de fundos públicos, redução da participação do BNDES como agente indutor de desenvolvimento, regulamentação da terceirização em atividades fins e uma substancial reforma das leis trabalhistas cujo impacto na geração de empregos parece ter sido nulo (sobre o tema, ver Krein, Gimenez \& Santos, 20I8). Quando Temer saiu do governo, com popularidade ínfima, o cenário de desemprego e recessão parecia permanente. A recente eleição de Jair Bolsonaro, com uma agenda econômica de forte inspiração liberal, não parece sinalizar para qualquer alteração no ambiente crítico.

Diante dos acontecimentos, elegemos a indústria automotiva brasileira como objeto para mensuração dos efeitos críticos a partir de 2008. A crise econômica brasileira, que já dura quase seis anos, compõe-se de uma série de fenômenos que vão além da economia, como já demonstramos, mas que demandariam investigações de maior fôlego: a crise das economias vizinhas, um volume muito maior de produção do que o historicamente percebido, a contenção do crédito ao consumo, o aumento de incertezas bancárias e a própria política autofágica de demissões ao primeiro sinal de perenidade da crise no setor au- 
tomotivo brasileiro. A isso, somam-se decisões governamentais de critérios contestáveis, como o desenho de políticas protecionistas travestidas de pacotes de incentivos à inovação e ao upgrading tecnológico, bem como decisões corporativas que não avançam no sentido da maior exploração industrial no Brasil. O país aparece hoje com percentual relevante de capacidade ociosa na produção automobilística, mantendo estáveis os seus níveis de produtividade (Confederação Nacional da Indústria, vários anos).

\section{METODOLOGIA}

O modelo teórico que embasa a presente análise remete às cadeias globais de valor (Gereffi, I994; Barrientos, Gereffi \& Rossi, 20I I; Gereffi \& Lee, 20I4), em uma formulação do tipo coordenada pelo produtor, ou producer-driven, em que as original equipment manufacturers (OEMs) ditam as diretrizes produtivas (Herrigel \& Wittke, 2005), promovendo a consolidação das redes globais de produção (Barrientos, Gereffi \& Rossi, 20I I). O recorte analítico, no entanto, se dá na forma da produção localmente observável, especificamente na escala regional. As unidades de análise são, portanto, os clusters produtivos que respondem a essas cadeias (Gereffi \& Lee, 20I4); são a forma de ordenamento local da produção, em organização cativa (geralmente no modelo follow sourcing), em resposta aos múltiplos estímulos a que tal organização está submetida (Gereffi, I994; Gereffi \& Lee, 20I4). Os estímulos, de acordo com a conformação proposta por Gereffi e Lee (20I4), envolvem as distintas formas de governança (privadas, social e pública), as regulações explícitas, como medidas de segurança veicular, parâmetros de emissão de gases, entre outros (Ford, 20I8), os pacotes de incentivos, como o Inovar-Auto e o Rota 2030, e as respostas locais aos estímulos, como as organizações laborais, ONGs, demandas difusas da sociedade civil etc. Dessa forma, busca-se concatenar os princípios da teoria da regulação, especificamente a organização do modo de regulação e as reações brasileiras às crises econômica e política nesse nível, com as abordagens mais recentes sobre estudos de cadeias globais de valor. Diante do advento conjuntural da crise econômica, observamos respostas institucionais (termos regulatórios e legais) e sua manifestação mais sensível em termos de emprego e renda nos objetos observáveis das cadeias. A partir dessa moldura analítica, tomamos por base as noções de social upgrading e social downgrading (Barrientos, Gereffi \& Rossi, 20I I) como um aporte para mensurar o que ocorre no período destacado em relação aos empregos em três regiões automotivas selecionadas, embora a classificação aqui proposta seja apenas análoga à dos autores, uma vez que se concentra, de acordo com sua tipologia, nos setores de high-skilled, technology-intensive work e knowledge-intensive work, pelas próprias características da indústria automobilística instalada no Brasil.

Para o mapeamento da cadeia automotiva brasileira em conformidade com a ancoragem teórica aqui disposta, elegemos as seguintes classes de 
produção para a seleção dos dados da Relação Anual de Indicadores Sociais (Rais/MTE): fabricação de pneumáticos e de câmaras de ar; fabricação de automóveis, camionetas e utilitários; fabricação de caminhões e ônibus; fabricação de cabines, carrocerias e reboques para veículos automotores; fabricação de peças e acessórios para o sistema motor de veículos automotores; fabricação de peças e acessórios para os sistemas de marcha e transmissão de veículos automotores; fabricação de peças e acessórios para o sistema de freios de veículos automotores; fabricação de peças e acessórios para o sistema de direção e suspensão de veículos automotores; fabricação de material elétrico e eletrônico para veículos automotores, exceto baterias; fabricação de peças e acessórios para veículos automotores não especificados anteriormente (Classificação Nacional de Atividades Econômicas 2.0). ${ }^{5}$ Não estão contemplados os setores de vendas ou recondicionamento, embora, cremos, estejam inseridos na análise os grupos mais fundamentais da produção automobilística. ${ }^{6}$

A abordagem comparativa se apoia na metodologia proposta por Charles Ragin (I997), com o objetivo de confirmar ou refutar hipóteses (Lijphart, I97I). O desenho proposto por Ragin transforma estudos de caso em estudos qualitativos comparados. De modo a otimizar a operacionalização empírica desta pesquisa, adotam-se como unidade de análise as regiões com seus agrupamentos industriais (clusters), que conformam os três objetos.

O método comparativo de Ragin envolve a definição de variáveis relevantes que serão avaliadas nos dois casos. O objetivo é elencar elementos controláveis e observáveis que ajudem a investigação da hipótese. A hipótese nula tende a contemplar os elementos que são comuns aos objetos (Ragin, I997), podendo combinar variáveis quantitativas e qualitativas. As variáveis de interesse aqui pesquisadas buscam compreender processos de upgrading/downgrading sociais e econômicos nas unidades analisadas de forma simplificada. Embora as variáveis econômicas e sociais possam estar em consonância (Barrientos, Gereffi \& Rossi, 20 I I), o que se observa, no caso brasileiro, é um pequeno transbordamento em termos sociais, principalmente por se tratar de um período crítico.

\section{OS DADOS}

Entre 2007 e 20I7, com relação ao número total de empregos do setor, observamos tendência positiva em Camaçari, comportamento instável no vale do $\mathrm{Pa}$ raíba fluminense (VPF) e comportamento declinante no Grande ABC Paulista $(A B C)$. Todas as regiões sofreram perdas de empregos formais em 2008 e 2009, apresentando, no entanto, recuperação em 20Io. O biênio 20Io/20I I é o de maior número de empregos formais no ABC e no VPF, ao passo que, em Camaçari, o forte crescimento se dá nos anos posteriores. O pico de crescimento recente 


\begin{tabular}{|c|c|c|c|c|c|c|c|c|c|c|c|}
\hline & 2007 & 2008 & 2009 & 2010 & 20 I I & 2012 & 2013 & 2014 & 2015 & 2016 & 2017 \\
\hline Camaçari & 7.583 & 7.577 & 7.162 & 7.705 & 7.685 & 8.726 & 9.747 & 9.887 & I0.665 & 9.682 & I0. 253 \\
\hline VPF & 6.079 & 7.312 & 6.687 & 8.957 & 9.710 & 8.988 & 9.364 & 7.662 & 6.688 & 6.727 & I0.288 \\
\hline $\begin{array}{l}\text { ABC } \\
\text { Paulista }\end{array}$ & $75.05 \mathrm{I}$ & 80.146 & 75.729 & 83.989 & 86.242 & 71.652 & 8I.I73 & 73.640 & $62.79 \mathrm{I}$ & 53.859 & 46.539 \\
\hline
\end{tabular}

Tabela I

Número de empregos formais da indústria automobilística, Camaçari, vale do Paraíba fluminense e Grande ABC Paulista, 2007-20I7

Fonte: Rais/MTE, 2007-20I7.

do VPF será tratado mais adiante.

Observadas as rendas médias do total das classes selecionadas para análise, tem-se clareza, em primeiro lugar, da distância entre os rendimentos médios da região que chamamos de tradicional antes dos novos territórios automotivos (gráfico I), o que já era perceptível desde as instalações das novas plantas, em função de os parâmetros para definição dos salários tomarem por critério as médias regionais e não setoriais. Nota-se que as médias não decrescem ao longo dos anos (embora apontem para tanto em 20I5), muito em função do sucesso das negociações coletivas do setor, nas quais se obteve recorrentemente aumento real.? As rendas médias no VPF são menores que as de Camaçari, o que pode ser explicado nas origens das instalações, atuação sindical errática na primeira região e dificuldade nas negociações subsequentes (Dulci, 20I5). As informações que a tabela anterior e o gráfico adiante nos fornecem refletem efeitos conjuntu-

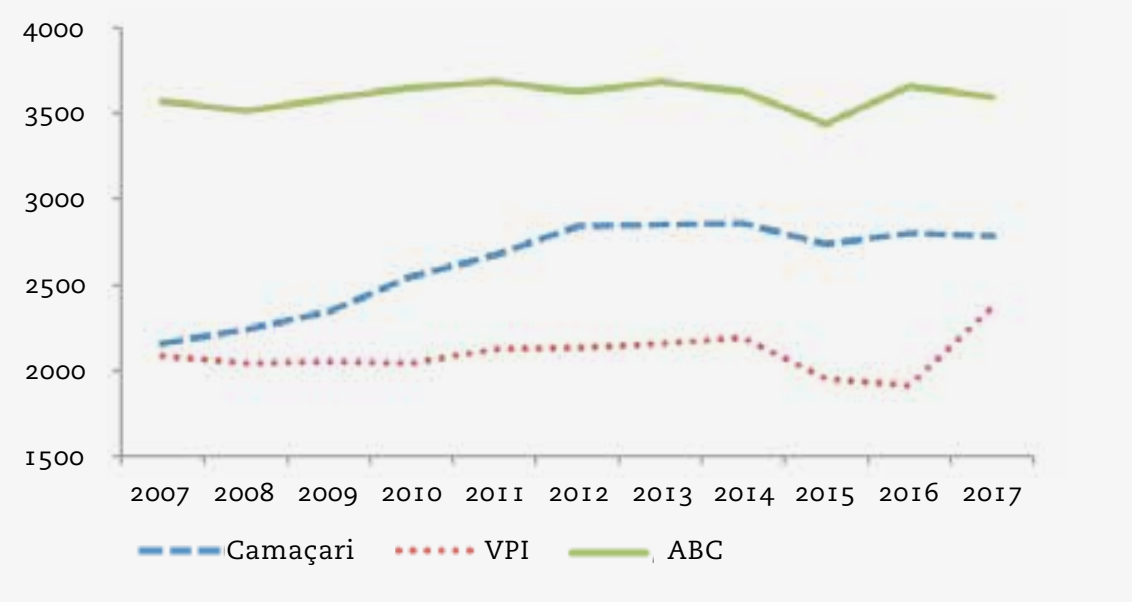

Gráfico I Renda média anual da indústria automobilística, Camaçari, vale do Paraíba fluminense e Grande ABC Paulista, 2007-20178

Fonte: Rais/MTE, 2007-20I5. 
rais percebidos em todo o país, mesmo no recrudescimento do período crítico recente. A elasticidade dos empregos ainda é maior que a da renda.

A seguir, optou-se pela análise específica de ocupações e de atividades econômicas, por região, de modo a facilitar a visualização das informações. Para cada região, observa-se o comportamento da renda e do número de empregos por classes de atividades e por grandes grupos de ocupações. ${ }^{9}$

Os dados da indústria automotiva refletem, em parte, as proteções que o setor recebeu do governo federal, em termos de incentivos e isenções, mais fortemente a partir da eclosão da crise internacional. Optamos por incluir 2007 para mostrar esse movimento de forma mais clara, uma vez que o ápice produtivo, salarial e empregatício da matriz automobilística não se deu antes da crise, mas ao longo do período analisado.

A Tabela 2 mostra, para cada região escolhida, o número de empregos por classificação de ocupação. Em Camaçari, há crescimento quase ininterrupto em todas as ocupações, o que mostra pouco efeito crítico na matriz em análise. Já no VPF, os cargos diretivos atingem seu ápice em 2009, iniciando queda nos anos seguintes, até 2017. O mesmo acontece com os profissionais ligados diretamente à produção. Percebe-se, no entanto, forte crescimento, entre 2010 e 20I3, dos técnicos de nível médio, o que denota uma troca de profissionais de um tipo menos qualificado por outro com instrução mais especializada. Os profissionais dos serviços administrativos e do comércio mantêm sua tendência de crescimento ante os primeiros anos da análise.

Por fim, no Grande ABC Paulista, há queda em praticamente todas as ocupações entre 20I I e 2012 (exceto entre os dirigentes e postos de nível superior), mas, principalmente, a partir de 20I3. As ocupações da produção perderam mais de 23, I mil postos de trabalho, o que representa $44,6 \%$ a menos de profissionais ocupados. Entre os dirigentes também houve perdas, com redução de I9,5\% de ocupações.

A Tabela 3 apresenta os números dos empregos formais nos setores ligados à indústria automotiva por classificação de atividades. A tendência observada quanto às ocupações se mantém para Camaçari, com leve queda na fabricação de autopeças em 20I6. Já com relação ao VPF, a crise econômica sentida no Brasil parece ter atingido com mais intensidade os setores de fabricação de automóveis e de caminhões e ônibus, a partir de 2014 (o último setor tende à oscilação por todo o período), mas já com indicação de forte recuperação no último ano. Nos setores de fabricação de cabines, carrocerias e reboques e de fabricação de autopeças, o declínio a partir de 2013 só se reverte em 2017. Parece estar parcialmente imune à situação o setor de fabricação de pneumáticos, em crescimento desde 20 Io e manutenção em níveis mais altos nos últimos anos. No grande $A B C$ Paulista, todos os setores apontam sinais críticos depois de 2013, ano em que a Anfavea (2018) registra o maior número de pessoas ocupadas na indústria automobilística desde 1986 e de maior produção de automóveis da história do país. 


\begin{tabular}{|c|c|c|c|c|c|c|c|c|c|c|c|}
\hline \multicolumn{12}{|l|}{ Camaçari } \\
\hline & 2007 & 2008 & 2009 & 2010 & $20 I I$ & 2012 & 2013 & 2014 & 2015 & 2016 & 2017 \\
\hline Dirigentes e prof. de ens. superior & 880 & 872 & 899 & 975 & I.I53 & I.I77 & I.364 & I.397 & I.37I & I.348 & I.229 \\
\hline Téc. nível médio & 5 I I & 548 & 6 13 & 652 & 609 & 766 & 803 & 892 & I.053 & 979 & 942 \\
\hline Serv. adm. e comércio & 263 & 294 & 255 & 299 & 298 & 439 & 460 & $4 \mathrm{I} 5$ & 480 & 447 & 685 \\
\hline Produção e manutenção & 5.928 & 5.862 & 5.394 & 5.779 & 5.625 & 6.344 & 7.120 & 7.183 & $7.76 \mathrm{I}$ & 6.908 & $7 \cdot 397$ \\
\hline Total & 7.583 & 7.577 & 7.162 & 7.705 & 7.685 & 8.726 & 9.747 & 9.887 & 10.665 & 9.682 & I0.253 \\
\hline \multicolumn{12}{|l|}{ VPF } \\
\hline & 2007 & 2008 & 2009 & 2010 & 20 I I & 2012 & 2013 & 2014 & 2015 & 2016 & 2017 \\
\hline Dirigentes e prof. de ens. superior & 582 & 789 & 792 & 719 & 494 & 512 & 605 & 627 & $56 \mathrm{I}$ & 718 & 1.538 \\
\hline Téc. nível médio & 767 & IOI9 & IOII & I340 & I909 & 1760 & 2297 & 2165 & I842 & I657 & 1978 \\
\hline Serv. adm. e comércio & 2 I I & 287 & 285 & 402 & $4 \mathrm{I} 5$ & 428 & 483 & 460 & 455 & 410 & 854 \\
\hline Produção e manutenção & 4.518 & 5.216 & 4.598 & 6.494 & $6.89 \mathrm{I}$ & 6.288 & 5.979 & 4.410 & 3.830 & 3.942 & 5.918 \\
\hline Total & 6.079 & $7 \cdot 312$ & 6.687 & 8.957 & 9.710 & 8.988 & $9 \cdot 364$ & 7.662 & 6.688 & 6.727 & I0.288 \\
\hline \multicolumn{12}{|l|}{ ABC Paulista } \\
\hline & 2007 & 2008 & 2009 & 2010 & 20 I I & 2012 & 2013 & 2014 & 2015 & 2016 & 2017 \\
\hline Dirigentes e prof. de ens. superior & 8.017 & 8.692 & 9.108 & 9.714 & I0.169 & I0.373 & I0.328 & 9.938 & $9 \cdot 368$ & 8.460 & 6.452 \\
\hline Téc. nível médio & 9.003 & 9.596 & 9.308 & I0.21 2 & 10.580 & 9.539 & I0.160 & 9.493 & 8.583 & 7.6 I5 & $6.8 \mathrm{I3}$ \\
\hline Serv. adm. e comércio & 6.035 & 6.197 & 5.995 & 6.3 II & 6.653 & 5.677 & 6.755 & 6.365 & $5 \cdot 58 \mathrm{I}$ & 4.924 & 4.419 \\
\hline Produção e manutenção & 51.988 & 55.648 & 5I.3I I & 57.745 & 58.828 & 46.053 & 53.913 & 47.834 & 39.255 & 32.817 & 28.802 \\
\hline Total & $75.05 \mathrm{I}$ & 80.146 & 75.729 & 83.989 & 86.242 & 71.652 & 8I.173 & 73.640 & 62.791 & 53.859 & 46.539 \\
\hline
\end{tabular}

Tabela 2

Número de empregos formais da indústria automobilística, por classificação de ocupação, Camaçari, vale do Paraíba fluminense e Grande ABC Paulista, 2007-2017

Fonte: Rais/MTE, 2007-2017. 


\begin{tabular}{|c|c|c|c|c|c|c|c|c|c|c|c|}
\hline & 2007 & 2008 & 2009 & 2010 & 20 II & 2012 & 2013 & 2014 & 2015 & 2016 & 2017 \\
\hline $\begin{array}{l}\text { Fabricação de pneumáticos e } \\
\text { de câmaras de ar }\end{array}$ & I.5I5 & I. 589 & $\mathrm{I} .43 \mathrm{I}$ & I. 758 & I.893 & 2. I I6 & $2.42 \mathrm{I}$ & 2.5 I8 & 2.548 & 2.835 & 2.924 \\
\hline $\begin{array}{l}\text { Fabricação de automóveis, } \\
\text { camionetas e utilitários }\end{array}$ & 3.672 & $3.6 \mathrm{IO}$ & 3.296 & $3 \cdot 523$ & 3.583 & 3.846 & 4.366 & 4.359 & $5 \cdot 323$ & 4.874 & $5.13 I$ \\
\hline Fabricação de autopeças & 2.302 & 2.279 & $2.33 \mathrm{I}$ & 2.317 & 2.209 & 2.635 & 2.826 & $2.88 \mathrm{I}$ & 2.794 & I.973 & 2.192 \\
\hline Total & 7.583 & 7.577 & 7.162 & 7.705 & 7.685 & 8.726 & 9.747 & 9.887 & 10.665 & 9.682 & 10.253 \\
\hline \multicolumn{12}{|l|}{ Vale do Paraíba fluminense } \\
\hline & 2007 & 2008 & 2009 & 2010 & $20 I I$ & 2012 & 2013 & 2014 & 2015 & 2016 & 2017 \\
\hline $\begin{array}{l}\text { Fabricação de pneumáticos e } \\
\text { de câmaras de ar }\end{array}$ & 910 & 930 & 815 & 915 & I.022 & I.066 & I.I8I & I. 400 & I.390 & I.4I5 & I.4I6 \\
\hline $\begin{array}{l}\text { Fabricação de automóveis, } \\
\text { camionetas e utilitários }\end{array}$ & 3.I I I & $3 \cdot 398$ & 3.235 & 4.092 & 4.396 & 4.420 & 4. 163 & 2.919 & 2.356 & 2.492 & 4.452 \\
\hline $\begin{array}{l}\text { Fabricação de caminhões e } \\
\text { ônibus }\end{array}$ & 264 & 704 & 5.77 & 834 & 943 & 697 & $82 I$ & 635 & 496 & 430 & I.300 \\
\hline $\begin{array}{l}\text { Fabricação de cabines, } \\
\text { carrocerias e reboques para } \\
\text { veículos automotores }\end{array}$ & 313 & 484 & $4 \mathrm{I} 8$ & 593 & 629 & 440 & 506 & 447 & 319 & 285 & 273 \\
\hline Fabricação de autopeças & I.48I & I.796 & I. 642 & 2.523 & 2.720 & 2.365 & 2.694 & $2.26 \mathrm{I}$ & 2.127 & 2.105 & 2.847 \\
\hline Total & 6.079 & $7 \cdot 312$ & 6.687 & 8.957 & 9.710 & 8.988 & 9.365 & 7.662 & 6.688 & 6.727 & 10.288 \\
\hline \multicolumn{12}{|l|}{ ABC Paulista } \\
\hline & 2007 & 2008 & 2009 & 2010 & 2011 & 2012 & 2013 & 2014 & 2015 & 2016 & 2017 \\
\hline $\begin{array}{l}\text { Fabricação de pneumáticos e } \\
\text { de câmaras de ar }\end{array}$ & 5.977 & 6.340 & 5.780 & 6.559 & $6.4 \mathrm{II}$ & 6.157 & 7.037 & 6.699 & 4.048 & $3.82 \mathrm{I}$ & 4.019 \\
\hline $\begin{array}{l}\text { Fabricação de automóveis, } \\
\text { camionetas e utilitários }\end{array}$ & 23.273 & 25.243 & 24.574 & 27.382 & 29.I78 & I7.477 & 27.413 & 25.537 & 22.765 & 20.446 & I 2.259 \\
\hline $\begin{array}{l}\text { Fabricação de caminhões e } \\
\text { ônibus }\end{array}$ & I4.005 & I 4.458 & I3.887 & I 4.886 & I6.I52 & I5.893 & I5.726 & I3.75I & I 2.596 & I0.630 & I I.509 \\
\hline $\begin{array}{l}\text { Fabricação de cabines, } \\
\text { carrocerias e reboques para } \\
\text { veículos automotores }\end{array}$ & 326 & $37 \mathrm{I}$ & 313 & 337 & 278 & 238 & 279 & 235 & 162 & 26 & 46 \\
\hline Fabricação de autopeças & 31.470 & 33.734 & 31.175 & 34.825 & 34.223 & 31.887 & 30.718 & 27.418 & 23.220 & I8.936 & I8.706 \\
\hline Total & $75.05 \mathrm{I}$ & 80.146 & 75.729 & 83.989 & 86.242 & 71.652 & 8I.I73 & 73.640 & $62.79 \mathrm{I}$ & 53.859 & 46.539 \\
\hline
\end{tabular}

Tabela 3

Número de empregos formais da indústria automobilística, por classificação de atividade, Camaçari, vale do Paraíba fluminense, Grande ABC Paulista, 2007-2017 $7^{10}$ Fonte: Rais/MTE, 2007-2017. 
A Tabela 4 (ver p.234) apresenta as médias salariais para as classificações de ocupações nas regiões selecionadas. O que se percebe, de modo geral, é uma relativa estabilidade, com tendências declinantes em alguns setores em 20I5. A elasticidade das rendas médias parece menor que a do número de empregos. Em Camaçari, os setores de dirigentes e profissionais de ensino superior e de serviços administrativos e funcionários ligados ao comércio apresentam resultados declinantes por período mais extenso, ao passo que o setor administrativo mostra sinais de melhora nos últimos anos. Os técnicos de nível médio e os profissionais da produção, mais numerosos, tendem à estabilidade. Já no vale do Paraíba fluminense, principalmente entre 2014 e 20I5, as médias salariais indicavam declínio, recuperado nos dois últimos anos. No Grande ABC, os salários parecem ter atingido seu ápice entre 20 I I e 20I3. No entanto, as quedas chegam a ı०\% dos ganhos reais, com relação aos cargos diretivos, I 3,5\% dos técnicos de nível médio, e $17,3 \%$ de aumento entre os profissionais administrativos, quando comparamos com 20I3. Salvo o setor de serviços administrativos e comércio, todos os outros observaram perdas considerando toda a série histórica.

Por fim, a Tabela 5 (ver p.235) nos mostra as médias salariais, por ano, das classificações de atividade selecionadas para as três regiões. Em Camaçari, a tendência geral é de estabilidade. No sul fluminense, as fabricações de pneus, caminhões e ônibus, cabines, carrocerias e reboques, e de autopeças foram as atividades mais atingidas pela crise por que passa o país. Os sinais se invertem em 20I7. Finalmente, no Grande $A B C$, as rendas mantêm tendência de estabilidade, com leve queda na fabricação de automóveis, caminhões e ônibus e cabines e carrocerias, mais especificamente em 2015.

De modo geral, a renda parece não ser uma variável tão sintomática da crise no setor, em função do alto grau de formalização e das garantias legais que ainda a sustentam. Os declínios muitas vezes são mais explicados por efeitos aritméticos (contingente de assalariados mais bem remunerados que deixam os postos de trabalho) do que como efeitos do período crítico, diferentemente do número de pessoas ocupadas.

\section{AS REGIÕES GANHADORAS E AS REGIÕES PERDEDORAS}

Saltam aos olhos os números recentes do vale do Paraíba fluminense, positivos em 20I7, e os do ABC Paulista em relação aos postos de trabalho, persistentemente negativos nos últimos anos. Aparentemente na contramão do momento crítico, os resultados do VPF refletem uma série de questões específicas que parecem indicar a saída da região de qualquer resquício de crise com relação à cadeia automotiva. As rendas médias dos dirigentes e profissionais de ensino superior aumentam muito, na casa dos $30 \%$, bem como o número de profissionais empregados nas ocupações de nível superior, de nível técnico e de serviços administrativos. Isso tudo se explica por um conjunto de movimentos que favoreceu a região, ajudando a explicar também por que se agudiza o processo crítico no ABC Paulista. 
234

\begin{tabular}{|c|c|c|c|c|c|c|c|c|c|c|c|}
\hline \multicolumn{12}{|l|}{ Camaçari } \\
\hline & 2007 & 2008 & 2009 & 2010 & $201 \mathrm{I}$ & 2012 & 2013 & 2014 & 2015 & 2016 & 2017 \\
\hline Dirigentes e prof. de ens. superior & $6.698,27$ & $6.809,06$ & $6.969,82$ & $7.251,66$ & $7.625,93$ & $7.900,92$ & $7.414,46$ & $7 \cdot 373,00$ & $6.912,97$ & $6.858,277$ & $6.442,307$ \\
\hline Téc. nível médio & $3 \cdot 182,25$ & $3 \cdot 323,88$ & $3.463,39$ & $3.834,6 \mathrm{I}$ & $3.419,92$ & $3 \cdot 386,49$ & $3.571,95$ & $3.452,64$ & 3.476, or & $3.622,007$ & $3.283,975$ \\
\hline Serv. adm. e comércio & $2.357,43$ & $2.342,79$ & $2.389,24$ & $2.340,02$ & $2.286,17$ & $2.356,56$ & $2.059,7 \mathrm{I}$ & I. 925,57 & I. 849,03 & I. 980,432 & $3.698,194$ \\
\hline Produção e manutenção & I. 387,00 & I. 449,40 & $\mathrm{I} .446,75$ & I.6I8,06 & I. 593,07 & I. 870,97 & $\mathrm{I} .95 \mathrm{I}, 57$ & I. 967,23 & I. $95 \mathrm{I}, 70$ & I. 949,805 & $2.036,45 \mathrm{I}$ \\
\hline Média & 2.157,9I & $2.236,36$ & 2.346, IO & $2.546,52$ & $2.669,84$ & $2.84 \mathrm{I}, 78$ & $2.854,65$ & $2.863,3 \mathrm{I}$ & $2.735,36$ & $2.803,699$ & $2.790,206$ \\
\hline \multicolumn{12}{|l|}{ Vale do Paraíba fluminense } \\
\hline & 2007 & 2008 & 2009 & 2010 & 20 II & 2012 & 2013 & 2014 & 2015 & 2016 & 2017 \\
\hline Dirigentes e prof. de ens. superior & $5.086,18$ & $4.984,08$ & $4.983,47$ & $5.785,62$ & $6.390,56$ & $6.585,93$ & $6.916,15$ & $6.534,29$ & $5.976,24$ & $4 \cdot 393,2$ I I & $6.201,043$ \\
\hline Téc. nível médio & $2.8 \mathrm{I0}, 6 \mathrm{o}$ & $2.774,26$ & $2.716,06$ & $2.746,06$ & $3.278,15$ & $3.326,05$ & $2.738,4 \mathrm{I}$ & $2.574,63$ & $2.300,80$ & $2.406,369$ & $2.66 \mathrm{I}, 99 \mathrm{I}$ \\
\hline Serv. adm. e comércio & $2.192,9 \mathrm{I}$ & $2.114,23$ & I.869,I6 & $2.485,18$ & $2.536,34$ & $2.226,28$ & $2.075,15$ & $2.05 \mathrm{I}, 88$ & I.698,6I & I. 773,524 & I. $918,63 I$ \\
\hline Produção e manutenção & I. 563,94 & I. 575,32 & I. 547,28 & I. $584, \mathrm{I} 5$ & I.609,06 & I. 568,26 & I.6I5,39 & I. 563,89 & I. 379,22 & I. 260,755 & I. 347,633 \\
\hline Média & $2.080,12$ & 2.13I, 26 & $2.144,56$ & 2.1 35,52 & $2.220,02$ & $2.229,63$ & $2.256,9 \mathrm{I}$ & $2.285,52$ & $2.040,37$ & I. 908,536 & $2.373,292$ \\
\hline \multicolumn{12}{|l|}{ ABC Paulista } \\
\hline & 2007 & 2008 & 2009 & 2010 & $201 \mathrm{I}$ & 2012 & 2013 & 2014 & 2015 & 2016 & 2017 \\
\hline Dirigentes e prof. de ens. superior & $7.689,19$ & $7.819,22$ & $7.831,40$ & $8.018,83$ & $7.960,63$ & $7.953,16$ & $7.914,88$ & $7.654,67$ & $7.236,72$ & 7.105,33 & 7.107,2I \\
\hline Téc. nível médio & $4.430,18$ & $4.591,63$ & $4.56 \mathrm{I}, 8 \mathrm{I}$ & $4.688,78$ & $4.689,7 \mathrm{I}$ & $4.516,26$ & $4.553,99$ & $4.35 \mathrm{I}, 97$ & $4.065,05$ & $4.016,67$ & $3.94 \mathrm{I}, 06$ \\
\hline Serv. adm. e comércio & $3.577,97$ & $3.673,89$ & $3.724,62$ & $3.820,8 \mathrm{I}$ & $3.897,77$ & $3.965,82$ & $3.833,8 \mathrm{I}$ & $3.822,78$ & $3.664,93$ & $3.782,68$ & $3.900,01$ \\
\hline Produção e manutenção & $2.787,56$ & $2.860,76$ & $2.873,87$ & $2.949,69$ & $2.986,33$ & $2.679,26$ & $2.535,02$ & $2.874,75$ & $2.617,43$ & $2.673,59$ & $2.684,09$ \\
\hline Total & $3.571,72$ & $3.668,50$ & $3.744,97$ & $3.812,89$ & $3.851,85$ & $3.789,03$ & $3.850,12$ & $3.791,99$ & $3.597,50$ & $3.659,76$ & $3.595,10$ \\
\hline
\end{tabular}

Tabela 4

Média salarial anual de rendimentos da indústria automobilística, por classificação de ocupação, Camaçari, VPF e Grande ABC Paulista, 2007-2017 (2007=100) Fonte: Rais/MTE, 2007-2017. 


\begin{tabular}{|c|c|c|c|c|c|c|c|c|c|c|c|}
\hline \multicolumn{12}{|l|}{ Camaçari } \\
\hline & 2007 & 2008 & 2009 & 2010 & $20 I I$ & 2012 & 2013 & 2014 & 2015 & 2016 & 2017 \\
\hline $\begin{array}{l}\text { Fabricação de pneumáticos e } \\
\text { de câmaras de ar }\end{array}$ & I. 935,84 & I. 872,03 & I. 998,47 & $2.04 \mathrm{I}, 63$ & 2.089, I I & 2.IOI, I4 & 2.I $44, \mathrm{I} 3$ & $2.205,42$ & $2 . \mathrm{II} 6, \mathrm{IO}$ & $2.095,07$ & $2.260,44$ \\
\hline $\begin{array}{l}\text { Fabricação de automóveis, } \\
\text { camionetas e utilitários }\end{array}$ & $2.60 \mathrm{I}, 25$ & $2.747,8 \mathrm{I}$ & $2.979,09$ & $3.228, \mathrm{I} 8$ & $3.44 \mathrm{I}, 4 \mathrm{I}$ & $3.706,53$ & $3.636,52$ & $3.689, \mathrm{OI}$ & $3.290,85$ & $3.419,48$ & $3 \cdot 327,68$ \\
\hline Fabricação de autopeças & I. 627,54 & I.710,38 & I. 709,35 & I. 940,48 & I. 916,00 & $2.228,38$ & $2.29 \mathrm{I}, 7 \mathrm{I}$ & $2.217,06$ & $2.24 \mathrm{I}, 8 \mathrm{I}$ & $2.300,73$ & $2.244,5 \mathrm{I}$ \\
\hline Média & $2.157,9 \mathrm{I}$ & $2.236,36$ & 2.346, IO & $2.546,52$ & $2.669,84$ & $2.84 \mathrm{I}, 78$ & $2.854,65$ & $2.863,3 \mathrm{I}$ & $2.735,36$ & $2.803,70$ & $2.790,2 \mathrm{I}$ \\
\hline \multicolumn{12}{|l|}{ Vale do Paraíba fluminense } \\
\hline & 2007 & 2008 & 2009 & 2010 & $201 \mathrm{II}$ & 2012 & 2013 & 2014 & 2015 & 2016 & 2017 \\
\hline $\begin{array}{l}\text { Fabricação de pneumáticos e } \\
\text { de câmaras de ar }\end{array}$ & $2.196,09$ & $2.236,88$ & 2.215, IO & $2.495,87$ & $2.668,7 \mathrm{I}$ & $2.939,79$ & $2.587,96$ & $2.219,36$ & $2.102,65$ & $2.084,15$ & $2.079,2 \mathrm{I}$ \\
\hline $\begin{array}{l}\text { Fabricação de automóveis, } \\
\text { camionetas e utilitários }\end{array}$ & $2.203, \mathrm{II}$ & $2.338,04$ & $2.386,99$ & $2.4 \mathrm{I} 2,49$ & $2.389,89$ & $2.332,26$ & $2.492,06$ & $2.7 \mathrm{II}, \mathrm{O} 3$ & $2.439,57$ & $2.592,03$ & $2.386,19$ \\
\hline $\begin{array}{l}\text { Fabricação de caminhões e } \\
\text { ônibus }\end{array}$ & I. 567,83 & I. 809,66 & I. $8 \mathrm{II}, 07$ & I. 847,93 & $2.02 \mathrm{I}, 36$ & $2.027,38$ & I.9I6,63 & I. 925,22 & I. $55^{8}, 50$ & I. 459,36 & $4 \cdot 387,47$ \\
\hline $\begin{array}{l}\text { Fabricação de cabines, } \\
\text { carrocerias e reboques para } \\
\text { veículos automotores }\end{array}$ & 2.065 , IO & $2.053,19$ & I. 9 I 2,80 & I. 999,26 & $2.208,40$ & $2.016,50$ & $2.036,73$ & I. $8 \mathrm{II}, 7 \mathrm{O}$ & I. 493,07 & I.407,66 & I.730,91 \\
\hline Fabricação de autopeças & I. 844,99 & I. 832,44 & I. 808,09 & I. $682,7 \mathrm{I}$ & I. 848,46 & I. $8 \mathrm{I} 6,96$ & I. 893,48 & I. 972, OI & I.75I,95 & I. $623,3 \mathrm{I}$ & I. $64 \mathrm{I}, 26$ \\
\hline Média & 2.080, I I & 2.I $3 \mathrm{I}, 26$ & 2.I 44,55 & $2.135,5 \mathrm{I}$ & $2.220,02$ & $2.229,62$ & $2.256,9 \mathrm{I}$ & $2.285,52$ & $2.040,37$ & I. 908,53 & $2.373,29$ \\
\hline \multicolumn{12}{|l|}{ ABC Paulista } \\
\hline & 2007 & 2008 & 2009 & 2010 & $201 \mathrm{II}$ & 2012 & 2013 & 2014 & 2015 & 2016 & 2017 \\
\hline $\begin{array}{l}\text { Fabricação de pneumáticos e } \\
\text { de câmaras de ar }\end{array}$ & $2.906,74$ & $2.842,33$ & $2.782,46$ & $2.926,7 \mathrm{I}$ & $2.943,52$ & $3.032,09$ & $2.865,94$ & $2.8 \mathrm{Io}, 16$ & $2.856,69$ & $2.99 \mathrm{I}, 43$ & $2.928,2 \mathrm{I}$ \\
\hline $\begin{array}{l}\text { Fabricação de automóveis, } \\
\text { camionetas e utilitários }\end{array}$ & $4.895,79$ & $5.073,80$ & $5.4 \mathrm{IO}, 82$ & $5.238,64$ & $4.989,87$ & $5.577,64$ & $5.063,65$ & $4.903,9 \mathrm{I}$ & $4 \cdot 364,09$ & $4.658,28$ & $4.534,34$ \\
\hline $\begin{array}{l}\text { Fabricação de caminhões e } \\
\text { ônibus }\end{array}$ & $4.910,08$ & $5.083,34$ & $4.726,22$ & $5 \cdot 323,02$ & $5 \cdot 525,50$ & $4 \cdot 993,33$ & $4.980,93$ & $4.909,92$ & $4.639,82$ & $4.95 \mathrm{I}, 56$ & $4.555,6 \mathrm{I}$ \\
\hline $\begin{array}{l}\text { Fabricação de cabines, } \\
\text { carrocerias e reboques para } \\
\text { veículos automotores }\end{array}$ & I. I 17,52 & I. 318,55 & I. 253,38 & I. 299,02 & I. 347, OI & I. 440,29 & I. $422,3 \mathrm{I}$ & I. 487,84 & I. $38 \mathrm{I}, 65$ & 958,98 & 937,38 \\
\hline Fabricação de autopeças & 2. 148,64 & 2.19I, 65 & 2. $198,2 \mathrm{I}$ & $2.237,59$ & $2.282,19$ & $2.372,15$ & $2.435,76$ & $2.455,30$ & 2.425, I I & $2.6 \mathrm{II}, 6 \mathrm{I}$ & $2.538,43$ \\
\hline Média & $3.571,72$ & $3.668,50$ & $3.744,97$ & $3.8 \mathrm{I} 2,89$ & $3.85 \mathrm{I}, 85$ & $3.789,03$ & $3.850,12$ & $3.79 \mathrm{I}, 99$ & $3.597,50$ & $3.889,89$ & 3.595 , IO \\
\hline
\end{tabular}

Tabela 5

Média salarial anual de rendimentos da indústria automobilística, por classificação de atividade, Camaçari, vale do Paraíba fluminense, Grande ABC Paulista, 2007-2017 (2007=100)

Fonte: Rais/MTE, 2007-2017. 
Em I992, Georges Benko e Alain Lipietz publicaram na França uma obra chamada Les régions qui gagnent ou As regiões ganhadoras, na sua tradução em português. Ali, deixavam na introdução uma pergunta sugestiva: região ganhadora é "uma região que se afirma (do ponto de vista dos empregos, da riqueza, da arte de viver) pela sua própria actividade, ou uma região que vive à custa das que perderam, até mesmo de uma parte de seus habitantes?" (Benko \& Lipietz, I994: 5). A resposta que ambos desenvolvem segue no primeiro sentido, muito mais positivo que o segundo. No entanto, se olharmos pela perspectiva brasileira e sua forma de inserção ainda frágil nas cadeias globais de valor (Sturgeon et al., 2013), caminhamos no sentido da segunda alternativa, sendo, pelo menos para a presente (pequena) amostra de casos, a relação sul fluminense/ABC Paulista uma demonstração disso.

Ao perceber o aumento quantitativo de rendimentos e números de postos de trabalho, principalmente nos cargos de nível superior, adensou-se aqui a pesquisa. De acordo com um informante ${ }^{\text {II }}$ que trabalha no setor de avaliação final da produção da MAN Latin America desde a fundação da Volks Caminhões e Ônibus, com a criação do grupo Tratton - uma joint-venture da Volks, da Scania e da MAN - houve a transferência de postos e funções que eram realizadas em São Bernardo do Campo. São de fato cargos de salários mais elevados, com necessidade de mão de obra especializada e de nível superior, criados em Resende às expensas de seus fechamentos em São Paulo. As remunerações são as mesmas que eram recebidas no ABC. Além disso, com a recriação de mais um turno de trabalho, outros postos foram abertos, esses majoritariamente ocupados por mão de obra do sul do Rio de Janeiro. Some-se a isso a abertura de novas plantas industriais de outras marcas na região, e tem-se uma região ganhadora tanto às expensas de outras regiões como por méritos de agregação de valor e de externalidades positivas próprias (embora, como já dito, em grau limitado).

Além de o ABC Paulista se situar no polo oposto ao vale do Paraíba fluminense, observa algumas de suas fábricas movimentarem-se rumo à porta de saída da região. Ramalho e Rodrigues (20I0) demonstram como a experiência adquirida a partir de diversos momentos críticos deram repertório aos trabalhadores do ABC para resistir a reveses. No entanto, a distância que se construiu do trabalho organizado e do tipo permanente em relação aos governos estadual e federal parece ter cortado importantes canais de comunicação, o que tende a representar um downgrade dos trabalhadores do tipo high-skilled, technology intensive em aspectos qualitativos de sua trajetória, como apontam Barrientos, Gereffi e Rossi (20I I).

\section{CONSIDERAÇÕES FINAIS}

Embora os dados aqui apresentados ainda não mostrem os efeitos do fechamento da fábrica da Ford de São Bernardo do Campo, os resultados serão, sem dúvida, problemáticos para a região. Resultados que podem chegar à Bahia, 
principalmente após a decisão do governo brasileiro de zerar as tarifas de automóveis e caminhões com o México, onde a Ford possui três plantas industriais, nos próximos dois anos, e das reformulações que a montadora anuncia sobre as plantas chinesas. Ao optar pela cadeia automobilística como unidade de análise, nos deparamos com uma disputa interna autofágica que, num cenário crítico, parece esgotar seus já limitados recursos de multiplicação. As respostas institucionais brasileiras parecem frágeis, principalmente no atual momento, conduzindo ao aguçamento da crise. As decisões em relação à organização do trabalho fragilizam o potencial de resistência dos trabalhadores com legislações mais flexíveis (como na recente reforma trabalhista), e iniciativas de cunho regulatório ou afastam (no caso das legislações ambientais, por exemplo, citadas no relatório da Ford), ou são inócuas na proteção aos empregos (exempli gratia Inovar-Auto ou a tentativa do estado de São Paulo de mediar a compra da planta de São Bernardo do Campo pela Caoa).

Ao observar os dados da indústria automotiva no período analisado, podemos indicar algumas tendências não convergentes. Das "novas" regiões, Camaçari parece não ter percebido grandes picos de crise, apresentando estabilidade em suas remunerações médias e saldo positivo de empregos em todas as classificações de ocupações analisadas. A região recebeu investimentos recentes de duas fábricas de pneumáticos, além de ter sido transferido para o Polo Industrial de Camaçari o setor de criação e construída a fábrica de motores da Ford. No sul do estado do Rio de Janeiro, a situação crítica parecia ter se agudizado nos últimos anos, em termos de rendimentos e de número de postos de trabalho, mas a autofagia pode ter salvado os saldos regionais. No entanto, se há uma região perdedora durante os anos subsequentes ao epicentro da crise econômica mundial, é o Grande ABC Paulista, a região "tradicional" em análise. $\mathrm{OABC}$ viu fecharem-se $28.5 \mathrm{I} 2$ postos de trabalho relacionados à indústria automotiva no período em questão, comparando 2007 com 2017, e 39.703 só entre 20I I (melhor ano da série) e 2017.

A hipótese de que o chão de fábrica sofre mais imediatamente os efeitos críticos apresenta, portanto, três comportamentos. Em Camaçari, onde não houve ainda grandes perdas, podemos refutá-la. Temos, no entanto a confirmação estrita da hipótese para o ABC, e uma alteração de perfil produtivo com maior exigência de qualificação no sul fluminense, que se vale de alterações estratégicas corporativas, tornando-se um caso desviante (Lijphart, I97 I). Tais resultados, à luz da teoria aqui utilizada, mostram o quão frágeis ainda estão determinados nós institucionais do país, que seguem a reboque das decisões corporativas das OEM em relação a suas subsidiárias e seus fornecedores. Ao observar os clusters industriais em questão, tem-se mais evidências dessa afirmação.

As causas e os efeitos da crise podem também ser lidos tomando por base outras informações da indústria automotiva. Em 20I2, aqui identificado como um ano que sinalizava um recrudescimento crítico, houve queda de qua- 
se US\$I 2 milhões no faturamento das empresas. Os números decresceram de US\$105,4 milhões para US\$93,9 milhões (Anfavea, 20I6: 36). O volume de investimentos estabilizou-se no patamar de 20I I (Anfavea, 20I6: 38), e o número de empregos vem reduzindo-se desde o final de $2013 \mathrm{em}$ velocidade acelerada. A perda de empregos parece ser efeito misto de reestruturações e fechamentos, uma vez que a produção e as vendas também caíram bastante no último triênio. Em 20I3, 3,7 milhões de veículos foram produzidos ante 3, I milhões em 20I4 e 2,7 milhões em 20I7. Os licenciamentos seguem igual tendência (Anfavea, 20I6). Além disso, embora o índice de produtividade formulado pela CNI não apresente queda substantiva, a capacidade ociosa do setor automobilístico brasileiro encontra-se no presente ano em $28,9 \%$ do potencial instalado, melhor que o pior aproveitamento, em setembro de $2016(36,4 \%)$, mas muito distante dos $9,2 \%$ de junho de 2010 , melhor ano da série histórica.

Naturalmente, não se pode ainda indicar as causas últimas do comportamento visto aqui, uma vez que seria necessário aprofundar a pesquisa. Também são limitadas as extrapolações sobre os dados, muito embora possa-se, a partir da metodologia testada neste trabalho, visualizar melhor efeitos derivados da análise da cadeia automotiva mundial, oriundos dos centros produtores e verificáveis em termos de emprego e renda nas unidades de análise aqui propostas.

Ao indicar as questões deste trabalho, teve-se a forte suspeita de que a eliminação de postos de trabalho seria sentida pelos trabalhadores da linha de produção, por ser uma hipótese observável ao longo da história (exempli gratia Cardoso, 1998). Além disso, percebeu-se que o core da produção automotiva (produção de automóveis, caminhões e ônibus) tem a capacidade de irradiar os efeitos críticos para os outros setores, embora os sinta de forma mais intensa. Ademais, com a retração econômica do país e os níveis de poder de compra em processo de refreio, o mercado consumidor não se mostra tão ativo, o que contribui negativamente para a crise do setor. É possível, por fim, identificar um comportamento com relação à crise econômica a partir dos dados levantados: a crise internacional surtiu seu efeito, de forma menos intensa, em 2009, mas seus resultados, potencializados com a crise política nacional dos últimos dois anos, são mais agudos no período mais recente.

Recebido em 08/og/20I9 | Revisto em 2I/I I/20I9 | Aprovado em 3I/03/2020

João Assis Dulci é professor do Departamento e do Programa de Ciências Sociais da Universidade Federal de Juiz de Fora e doutor em sociologia pelo Instituto de Estudos Sociológicos e Políticos da Universidade do Estado do Rio de Janeiro. Atua nas áreas de sociologia econômica e sociologia do trabalho, com enfoque nos temas de desenvolvimento, mercado industrial brasileiro, indústria automobilística e impulsos para o desenvolvimento regional. 


\section{NOTAS}

I A teoria da regulação tem como objetivo compreender as crises inerentes ao capitalismo. Baseia-se em quatro conceitos básicos: o modo de produção, conforme consolidado pela teoria marxiana (Marx, 2005); o regime de acumulação, que envolve os elementos garantidores de regularidades da acumulação capitalista; os modos de regulação, conformando os instrumentos institucionais/legais nacionalmente construídos em compasso com o conceito anterior e organizadores do quarto conceito; e a organização do trabalho, que versa sobre a organização fabril, bem como sobre a divisão do trabalho (Lipietz, I989; Boyer, I990).

2 Não se pretende aqui um esforço no sentido de esgotar o desmanche do compromisso fordista. Para entender o desmanche nos termos regulacionistas ou pela via marxista, ver Sassen (I988); Lipietz (I989); Boyer (I990; I994); Harvey (I992, 2008, 20II); Dreifuss (I996); Boltanski \& Chiapello (2009), entre outros.

3 Problematizamos a utilização desse conceito para o caso brasileiro em Dulci (20I5, 20I8), apontando para a necessidade de uma adjetivação do tipo greenfield setorial, bem como reforçamos a ideia de que se deva analisar greenfields brasileiros em uma escala menor, que aponte a interação inter-regional nacional.

4 Identificamos em outro trabalho que, no caso do vale do Paraíba fluminense, percebe-se uma transposição da dualidade greenfield $\mathrm{x}$ brownfield para o nível microrregional, uma vez que as duas montadoras pioneiras do sul do estado recusavam quase explicitamente a contratação de mão de obra oriunda ou relacionada à CSN e seu passado sindical, ainda muito recente na região (Dulci, 20I5). Ao longo da década de 2000 e 2010, mais duas montadoras instalaram-se na região, atraindo também fábricas de pneumáticos, produtos químicos, bem como fomentando a integração com um dos braços siderúrgicos da CSN, em Barra Mansa, o que fortalece nossa convicção quanto à forte integração produtiva, material e social do vale do Paraíba fluminense e de grande parte do Sul Fluminense.

5 A classificação de fabricação de baterias e acumuladores para veículos automotivos, código $2722-8$, não retorna postos de trabalho ou unidades produtivas nas regiões analisadas. 
6 A opção se deve ao fato de o primeiro grupo fazer parte da cadeia de comércio, ao passo que o segundo contempla negócios muito pequenos e pouco elásticos às vendas de automóveis novos (podendo, na verdade, funcionar como um indicador de comportamento inversamente proporcional à produção de novos automóveis). Por lidar com regiões cujos números agregados são muito distintos, optamos, em grande parte do texto, pela análise de dados proporcionais. Em alguns momentos, trataremos dos números absolutos.

7 Como já havíamos percebido em trabalho anterior, a política de médias regionalizadas de renda é uma das grandes diferenças entre Camaçari e o VPF, onde se percebeu uma herança um tanto "perversa" da crise gerada pela privatização da CSN (Dulci, 20I5).

8 Valores deflacionados pelo IPCA, tendo 2007 como ıоo.

9 Optamos por excluir da visualização os setores nos quais não constam trabalhadores ou aqueles que totalizam menos de 20 empregos, em média, uma vez que sua oscilação extremamente elástica turva análises mais sólidas. As categorias de ocupação que criamos foram: dirigentes e profissionais de ensino superior, que reúne membros superiores do poder público, dirigentes de organizações de interesse público e profissionais das ciências e das artes; técnicos de nível médio, equivalente a essa categoria; serviços administrativos e comércio, que inclui trabalhadores de serviços administrativos; trabalhadores dos serviços, vendedores do comércio em lojas e mercados; produção e manutenção, que congrega trabalhadores da produção de bens e serviços industriais (categorias 7 e 8 da CBO) e trabalhadores em serviços de reparação e manutenção.

Io Optamos por unir as categorias fabricação de peças e acessórios para o sistema motor de veículos automotores, fabricação de peças e acessórios para os sistemas de marcha e transmissão de veículos automotores", "Fabricação de peças e acessórios para o sistema de freios de veículos automotores, fabricação de peças e acessórios para o sistema de direção e suspensão de veículos automotores, fabricação de material elétrico e eletrônico para veículos automotores, exceto baterias e fabricação de peças e acessórios para veículos automotores não especificados anteriormente sob a categoria fabricação de autopeças. 
I I Por receio de represálias, o informante pediu anonimato. O contato se deu através de uma rede do tipo "bola de neve", via e-mail. A partir das informações percebidas na análise quantitativa da mudança de perfil dos empregados de Resende, especificamente na fabricação de caminhões e ônibus, formularam-se quatro perguntas, que versavam sobre mudanças na hierarquia da planta em questão; alteração nas remunerações; alteração do perfil contratado; motivação para a vinda de novos funcionários.

\section{REFERÊNCIAS BIBLIOGRÁFICAS}

Andrade, Maria da Conceição Borges. (2009). O uso do território no contexto da reestruturação produtiva: o caso do polo industrial de Camaçari. In: Encuentro de Geógrafos de America Latina, I2. Montevideo. Anais..., I.

Anfavea. (2018). Anuário da indústria automobilística brasileira. São Paulo: Anfavea.

Anfavea. (2016). Anuário da indústria automobilística brasileira. São Paulo: Anfavea.

Appy, Bernard. (1993). Questão fiscal: crise e concentração de renda. In: Ires/Desep. Crise brasileira - anos oitenta e governo Collor. São Paulo: Cajamar.

Arbix, Glauco. (2006). Guerra fiscal, espaço público e indústria automobilística no Brasil. In: Cardoso, Adalberto \& Covarrubias, Alex (orgs.). A indústria automobilística nas Américas - a reconfiguração estratégica e social dos atores produtivos. Belo Horizonte: Editora da UFMG.

Barrientos, Stephanie; Gereffi, Gary \& Rossi, Arianna. (20II). Economic and social upgrading in global production networks: a new paradigm for a changing world. International Labour Review, I50/3 4, p. 319-340.

Bedê, Marco Aurélio. (1997). A política automotiva nos anos 90. In: Arbix, Glauco \& Zilbovicius, Mauro. De JK a FHC - a reinvenção dos carros. São Paulo: Scritta.

Benko, Georges \& Lipietz, Alain. (1994). As regiões ganhadoras - distritos e redes: os novos paradigmas da geografia econômica. Oeiras: Ed. Celta.

Boltanski, Luc \& Chiapello, Ève. (2009). O novo espírito do capitalismo. São Paulo: WMF Martins Fontes. 
Boyer, Robert. (I994). As alternativas ao fordismo - dos anos 80 ao século XXI. In: Benko, Georges \& Lipietz, Alain. As regiões ganhadoras - distritos e redes: os novos paradigmas da geografia econômica. Oeiras: Ed. Celta.

Boyer, Robert. (1990). A teoria da regulação - uma análise crítica. São Paulo: Nobel.

Boyer, Robert \& Freyssenet, Michel. (2003). Los modelos productivos. Madrid: Editorial Fundamentos.

Cardoso, Adalberto. (2006). A nova face da indústria automobilística brasileira ou a tese da convergência revisitada. In: Cardoso, Adalberto \& Covarrubias, Alex (orgs.). A indústria automobilística nas Américas - a reconfiguração estratégica e social dos atores produtivos. Belo Horizonte: Editora da UFMG. Cardoso, Adalberto. (1998). Trabalhar, verbo transitivo: trajetórias ocupacionais de trabalhadores da indústria automobilística. Dados, 4I/4, p. 70I-750.

Castells, Manuel. (2007). A sociedade em rede, v. I. São Paulo: Paz e Terra.

Castro, Nádia Araújo. (I988). Novo operariado, novas condições de vida e trabalho nas fronteiras do moderno capitalismo industrial brasileiro. Encontro Nacional de Estudos Populacionais, 6, Olinda. Anais..., 2, p. 437-482.

Ciccolella, Pablo José. (1992). Reestructuración industrial y transformaciones territoriales: consideraciones teóricas y aproximaciones generales a la experiencia argentina. Universidad de Buenos Aires, Instituto de Geografía, Facultad de Filosofía y Letras. Disponível em http://ww2.filo.uba.ar/ contenidos/investigacion/institutos/geografia/ territ4. htm. Acessado em I9 maio 2017.

Confederação Nacional da Indústria. (vários anos). Indicadores industriais.

Comin, Álvaro. (2006). A nova onda de desenvolvimento da indústria automobilística brasileira. In: Cardoso, Adalberto \& Covarrubias, Alex (orgs.). A indústria automobilística nas Américas - a reconfiguração estratégica e social dos atores produtivos. Belo Horizonte: Editora da UFMG.

Comin, Álvaro. (200I). Verdades e mentiras sobre a onda recente de penetração estrangeira no Brasil. Indicadores Econômicos FEE, 28/4, p. I6I-I82. 
Covarrubias, Alex. (2006). Divergências convergentes na transformação das práticas de emprego - Estudos de caso da indústria automobilística no México e no Brasil. In: Cardoso, Adalberto; Covarrubias, Alex. A indústria automobilística nas Américas - a reconfiguração estratégica e social dos atores produtivos. Belo Horizonte: Ed. UFMG.

Dreifuss, René. (1996). A época das perplexidades - mundialização, globalização e planetarização: novos desafios. Petrópolis: Vozes.

Dulci, João Assis. (20I8). Configurações do desenvolvimento em duas novas regiões automobilísticas: sul fluminense e Camaçari (BA). Política \& Trabalho, I/48, p. 75-94.

Dulci, João Assis. (2016). A trajetória recente do desenvolvimento no Brasil. Faces de Clio, 2/3, p. I55-185.

Dulci, João Assis. (2015). Desenvolvimento regional e mercado de trabalho em perspectiva comparada: Vale do Paraíba Fluminense e Camaçari (BA). Tese de Doutorado. PPGS/Universiade do Estado do Rio de Janeiro.

Dulci, Otávio Soares. (2009). Economia e política na crise global. Estudos Avançados, 23/65, p. I05-II9.

Dulci, Otávio Soares. (2002). Guerra fiscal, desenvolvimento desigual e relações federativas no Brasil. Revista de Sociologia e Política, I8, p. 95-107.

Ferraz, João Carlos et al. (1996). Made in Brazil. Rio de Janeiro: Ed. Campus.

Ford. (20I8). Annual report on form Io-k. Michigan.

Gereffi, Gary. (I994). The organization of buyer-driven commodity chains: how US retailers shape overseas production networks. In Korzeniewics, Miguel \& Gereffi, Gary. Commodity chains and global capitalism. Westport/London: Praeger, P.95-I 22.

Gereffi, Gary \& Lee, Joonkoo. (20I4). Economic and social upgrading in global value chains and industrial clusters: why governance matters. Journal of Business Ethics, I33/I, p. 25-38.

Harvey, David. (20I I). O enigma do capital. São Paulo: Boitempo.

Harvey, David. (2008). Neoliberalismo - história e implicações. São Paulo: Loyola. 
Harvey, David. (2005). A produção capitalista do espaço. São Paulo: Annablume.

Harvey, David. (I992). A condição pós-moderna. São Paulo: Ed. Loyola.

Herrigel, Gary \& Wittke, Volker. (2005). Varieties of vertical disintegration: the global trend toward heterogeneous supply relations and the reproduction of difference in US and German manufacturing. Industry Studies Association Working Papers. Pulmann: ISA.

IBGE. (2008). Regiões de influência das cidades. Rio de Janeiro.

Krein, José Dari; Gimenez, Denis M. \& Santos, Anselmo L. dos. (20I8). Dimensões críticas da reforma trabalhista no Brasil. Campinas: Curt Nimuendajú.

Leite, Márcia de Paula. (2000). Desenvolvimento econômico local e descentralização na América Latina: a experiência da Câmara regional do Grande $A B C$ no Brasil. Santiago de Chile: Cepal.

Lijphart, Arend. (I97I). Comparative politics and the comparative method. American Political Science Review, 65/3, p. 682-693.

Lima, Raphael. (2005). Açúcar, coca-cola e automóveis: ação político-empresarial na construção de um "município modelo" em Porto Real (RJ). Dissertação de Mestrado. PPGSA/Universidade Federal do Rio de Janeiro.

Lipietz, Alain. (1989). O fordismo periférico. Ensaios FEE, Io/2.

Marx, Karl. (2005) [1859]. Introdução. In: Contribuição à crítica da economia política. São Paulo: Martins Fontes.

Mendes, Vítor Marcelo Oliveira. (2006). A problemática do desenvolvimento em Salvador: análise dos planos e práticas da segunda metade do século XX (I950-2000). Tese de Doutorado. PPGPUR/Universidade Federal do Rio de Janeiro.

Nabuco, Maria Regina et al. (2002). Indústria automotiva: a nova geografia do setor produtivo. Rio de Janeiro: DP\&A.

Novick, Marta. (200I). Nuevas reglas de juego en la Argentina, competitividad y actores sindicales. Buenos Aires: Enrique de la Garza Toledo ed.

Oliveira, Francisco. (I999). Os cavaleiros do antiapocalipse: trabalho e política na indústria automobilística. São Paulo: Entrelinhas/Cebrap. 
Oliveira, Francisco. (1993). Quanto melhor, melhor: o acordo das montadoras. Novos Estudos Cebrap, 36, p. 3-7.

Olivera, Guadarrama. (200I). Implicaciones económicoterritoriales del auge exportador mexicano. Estudios Demográficos y Urbanos, 16/2, p. 375-413.

Paasi, Anssi. (2000). Re-constructing regions and regional identity. Nijmegen: Nethur Lecture.

Pessoti, Bruno Casseb \& Pessoti, Gustavo Casseb. (2010). A economia baiana e o desenvolvimento industrial: uma análise do período I978-2010. Revista de Desenvolvimento Econômico, 28/22.

Radosevic, Slavo \& Rozeik, Andrew. (2005). Foreign direct investment and restructuring in the automotive industry in Central and East Europe. Working Paper, 53.

Ragin, Charles. (1997). The comparative method: moving beyond qualitative and quantitative strategies. Berkeley: University of California Press.

Ramalho, José Ricardo. (2005). Novas conjunturas industriais e participação local em estratégias de desenvolvimento. Revista Dados, 48/3.

Ramalho, José Ricardo \& Rodrigues, Iram Jácome. (2010). Sindicato, crise econômica e estratégias regionais novas dimensões da participação política no ABC Paulista. Caderno CRH, 23/59, p. 339-35I.

Santana, Marco Aurélio. (2010). Ruptura geracional induzida e estratégias de gestão: a experiência nas montadoras do sul fluminense. Revista Educação e Sociedade, 3I/III.

Sassen, Saskia. (1988). The mobility of capital and labour. Cambridge: Cambridge University Press.

Sturgeon, Timothy et al. (2013). O Brasil nas cadeias globais de valor: implicações para a política industrial e de comércio. Revista Brasileira de Comércio Exterior, II5, p. 26-4I.

Torres, Ricardo \& Cário, Sílvio. (2012). O mito da industrialização como desenvolvimento: o comando do excedente na cadeia mercantil da indústria automobilística brasileira Revista da Sociedade Brasileira de Economia Política, 33, p. 39-7I. 
246

Van Tulder, Rob \& Ruigrok, Winifred. (I998). European cross-national production networks in the auto industry: Eastern Europe as the low end of European car complex. Berkeley roundtable on the international economy.

Vega, Maria Carmen. (2004). El desarrollo de la industria de la maquila en México. Problemas del Desarrollo. Revista Latinoamericana de Economía, 35/138. 
Palavras-chave

Indústria automotiva;

crise econômica;

desemprego;

desenvolvimento regional;

regiões ganhadoras.

Keywords

Automotive industry; economic crisis; unemployment; regional development; winning regions.
CRISE, EMPREGO E RENDA NA INDÚSTRIA AUTOMOTIVA: OS CASOS DO SUL FLUMINENSE, CAMAÇARI E GRANDE ABC PAULISTA EM PERSPECTIVA COMPARADA

\section{Resumo}

À luz das recentes ondas de investimento estrangeiro da indústria automobilística brasileira, a partir da década de I990, este artigo analisa a trajetória de emprego e renda no setor automotivo, diante das crises econômica de 2008 e política dos últimos anos, observando comportamentos em três casos, em perspectiva comparada - o Grande ABC Paulista, a região tradicional; o vale do Paraíba fluminense e Camaçari (BA), as novas regiões -, tomando a cadeia produtiva como escopo e os clusters como unidade analítica. A hipótese testada é de que os primeiros impactos críticos atingem os setores menos qualificados e os empregos do "chão de fábrica". o que se percebe é que em cada região resulta um comportamento distinto, sendo a região tradicional a que mais se comporta de acordo com a hipótese, e as novas regiões apresentando comportamentos discrepantes.

CRISIS, EMPLOYMENT AND INCOME IN THE AUTOMOTIVE INDUSTRY: THE CASES OF SUL FLUMINENSE, CAMAÇARI AND ABC PAULISTA IN COMPARATIVE PERSPECTIVE

\section{Abstract}

Considering the recent foreign investment waves in the Brazilian automotive industry, since the I990's, this paper analyses the employment and income trajectory in the automotive sector, in face of the economic crisis of 2008 and the policies of the last years. It observes the behaviour in three cases, in a compared perspective - the Grande $A B C$ Paulista, the traditional region; the vale do Paraíba fluminense and Camaçari (BA), the new regions -, taking the productive chain as scopes and the clusters as analytical units. The tested hypothesis is that the first critical impacts strike the less qualified sectors and the "shop-floor" jobs. What can be understood is that each region behaves in a distinguished way, in which the traditional region is the one that behaves the closer according to the hypothesis. The new regions present more discrepant behaviours. 